\title{
A study of future physics teachers' knowledge for teaching: A case of a decibel sound level scale
}

\author{
Marina Milner-Bolotin ${ }^{1}$ and Rina Zazkis ${ }^{2}$ \\ ${ }^{1}$ Department of Curriculum and Pedagogy, Faculty of Education, \\ University of British Columbia, Vancouver, Canada \\ ${ }^{2}$ Faculty of Education, Simon Fraser University, Burnaby, Canada
}

This study examines future secondary physics teachers' knowledge related to the teaching of sound waves, and specifically the topics of sound level and sound intensity. The data is comprised of future teachers' responses to a task in which they had to compose a script for an imaginary dialogue between a teacher and a group of students and to provide a commentary elaborating on their instructional choices. The topics selected for the task were chosen intentionally as they provide authentic and rich opportunities to bridge mathematics and science concepts, while challenging future teachers to consider the logarithmic measurement scale and its role in science. The task provided the participants with the beginning of a dialogue that featured student confusion about the measurement of sound level using a decibel scale. Future physics teachers were asked to extend this dialogue through describing envisioned instructional interactions that could have ensued. The instructional interchange related to the relationship between sound intensity and sound level, and particular teachers' responses to the student ideas related to the meaning of a decibel sound level scale were analysed. These responses were categorized as featuring superficial or deep, and conceptual or procedural knowledge for teaching. We describe each category using illustrative excerpts from the participants' scripts. We conclude with highlighting the affordances of scriptwriting for teachers, teacher educators, and researchers.

\section{ARTICLE DETAILS}

LUMAT General Issue Vol 9 No 1 (2021), 336-365

Received 20 February 2021 Accepted 5 May 2021

Published 28 May 2021

Pages: 30

References: 48

Correspondence:

marina.milner-

bolotin@ubc.ca

https://doi.org/10.31129/ LUMAT.9.1.1519

Keywords: knowledge for teaching, lesson play, logarithms, scriptwriting, sound level, physics teacher education

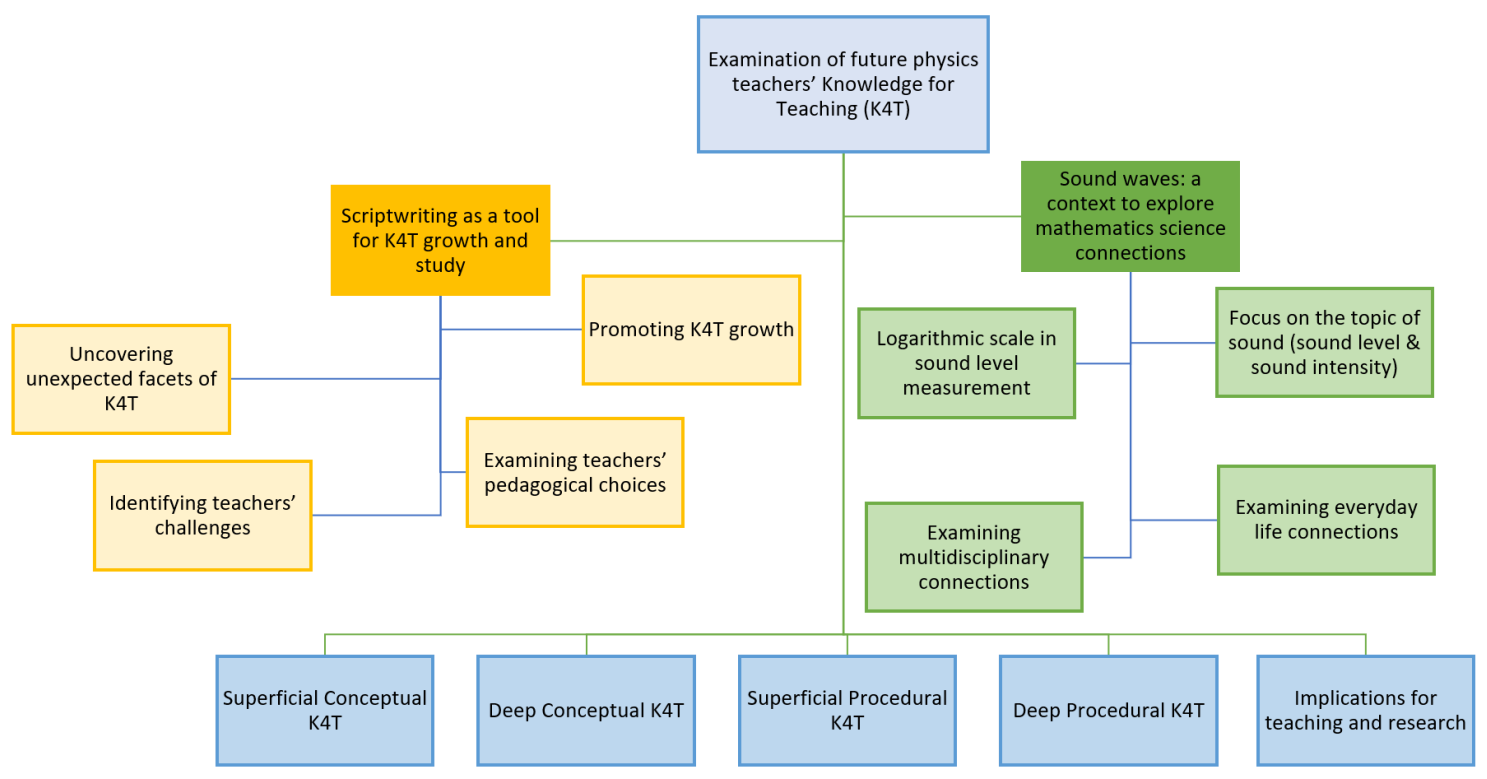


Exploring ways to describe and strengthen teachers' knowledge has long been of interest to science educators and researchers. Ample attention has been paid to the concepts that pose difficulties for learners in order to propose pedagogical approaches to address them, such as the concepts of electric current, forces, etc. (McDermott, 2001; McDermott et al., 2006). Within this general avenue of science education research, we focus on the topic of sound, specifically, sound level and sound intensity.

We engaged a group of future physics teachers in extending an imaginary dialogue between a teacher and several students, in which a student exhibited confusion about the measurement of sound level and the meaning of the differences in measures expressed in decibels. Our analysis of the scripted dialogues examined the teachers' knowledge for teaching utilized in the envisioned instructional interactions.

\section{Background}

In this section, we first describe different aspects of teachers' knowledge, focusing on the knowledge needed for teaching. Then, we introduce scripting tasks, a particular kind of task related to approximation of practice, used both to reveal and strengthen teachers' knowledge. We proceed with a brief overview of the concepts related to sound level and sound intensity and conclude with describing prior education research on sound and logarithms.

\subsection{Knowledge for Teaching (K4T)}

Teachers' knowledge and practice have received substantial attention in education research. Following Shulman's (1986, 1987) classical studies, and his distinction between Content Knowledge (CK or Subject Matter Knowledge SMK) and Pedagogical Content Knowledge (PCK), researchers proposed various elaborations on the components of knowledge needed for teaching. Contemporary frameworks focusing on knowledge for teaching (K4T) have expounded on a variety of additional facets. These include the familiarity with the subject and its overall structure, understanding how the subject matter relates to other subjects and everyday life, awareness of potential student difficulties and willingness to use modern technologies to support student learning (Milner-Bolotin, 2019, 2020). Moreover, descriptions of K4T often highlight topics related to the current state of affairs in the field of education, such as contemporary advances in educational technologies, ethical challenges, student 
engagement, and unsolved problems. Researchers appear to agree that subjectspecific K4T is paramount for effective teaching and this pertains to teaching all subjects, including elementary or secondary mathematics (e.g., Zazkis \& Zazkis, 2011) and science (Campbell et al., 2014; Depaepe et al., 2013).

Our research stems from a position that deep and comprehensive understanding of subject matter is a cornerstone of effective pedagogy (Biggs, 1987). Yet, it is well known that an undergraduate science degree hardly guarantees the depth and breadth of knowledge necessary for successful secondary school teaching. For example, researchers have measured the gain in conceptual knowledge acquired by students in introductory science courses. These studies documented that a significant number of undergraduates fail to transcend factual memorization (Hake, 1998).

The realization that subject-matter knowledge is essential for successful teaching and not all teachers might possess it is not new (Shulman, 1986). It has been a key concern of previous education reforms, such as the science and mathematics education reforms of the 1960's, 1980's, and 2000's (Center for Education Reform, 2018). Many notable scientists and mathematicians have collaborated with educators to produce textbooks and resources for elementary, secondary, and even postsecondary teachers (Arons, 1997; Feynman, 1994; Klein, 2004).

Advancing teachers' knowledge is the main goal of teacher education and professional development. Therefore, we should move beyond the general claims of labelling teachers' K4T as "lacking" and to understand the specific details pertaining to particular topics relevant to teaching. This leads to a question: How is it possible to gain access to K4T of a group of future physics teachers in order to design and adjust subsequent instruction? One possibility is to engage teachers in writing a script for a lesson, a method that we elaborate next.

\subsection{Lesson play and scripting approaches}

Scriptwriting, a valuable pedagogical strategy and an innovative research tool, was originally developed in the context of mathematics teacher education (Zazkis et al., 2013). While scriptwriting was novel in mathematics education research, its roots trace to the Socratic dialog and to the style of Lakatos' (1976) evocative 'Proofs and Refutations' in which a fictional interaction between a teacher and students interrogates mathematical claims.

Initially, scriptwriting was introduced in mathematics teacher education as a lesson play, where participants script interactions between an imaginary teacher- 
character and student-character(s) (Zazkis et al., 2009). Juxtaposed with a classical lesson plan describing merely content and activities, the lesson play aims at revealing how teaching-learning interactions might unfold. In later research, the lesson play approach was extended to an activity of writing an imaginary dialogue that is not necessarily restricted to a lesson, referred to as scriptwriting. In teacher education, scriptwriting opens doors for "approximations of practice", which "include opportunities to rehearse and enact discrete components of complex practice in settings of reduced complexity" (Grossman et al., 2009, p. 283), thus becoming especially valuable for teacher preparation.

Scriptwriting is both an instructional tool and a research data collection tool. It has been implemented in recent research (Kontorovich \& Zazkis, 2016; Zazkis \& Kontorovich, 2016; Zazkis \& Marmur, 2018; Zazkis et al., 2013; Zazkis \& Zazkis, 2011), where participants had to identify problematic issues in the presented topics, and subsequently clarify these by designing a scripted dialog. The affordances of scriptwriting for future teachers, teacher educators, and researchers were detailed in the aforementioned studies.

For teachers, writing a script is an opportunity to examine a personal response to a situation, explore erroneous or incomplete approaches of students, revisit and possibly enhance personal understandings of the concepts involved, and enrich the repertoire of potential responses to be used in future teaching. Challenging future teachers to think about the science content from this teaching perspective could encourage them to consult more advanced science resources. Moreover, while the teachers' ability to anticipate and address potential student difficulties depends on the teachers' experience, novice teachers can learn from other educators' experiences. This could motivate future teachers to consult science education literature. Thus, the scriptwriting activity helps uncover and draw on students' prior knowledge, while imagining a lesson as an interactive "living process", as opposed to following a previously designed rigid lesson plan.

For researchers, the scripts result in a rich data source that can be scrutinized from various perspectives, providing a lens for examining images of teaching and insights into the scriptwriter's understanding of the subject matter (Zazkis \& Kontorovich, 2016). Scripts composed by teachers may reveal not only their K4T relevant to a particular concept, but also their own difficulties and misunderstandings. 
For teacher educators, the scripts provide insights into planned pedagogical approaches that can be consequently highlighted and discussed in working with teachers. Furthermore, scripts composed by future teachers provide teacher educators with a view on the relevant knowledge of their students, which can subsequently be incorporated into instructional activities aimed at extending and strengthening this knowledge (Zazkis \& Marmur, 2018).

The chosen science content for our investigation is sound and sound level, which is ultimately related to a logarithmic scale. A brief overview of this topic is provided in the next section.

\subsection{A brief physics overview: Sound level and a logarithmic scale}

Sound is a mechanical wave (Hawkes et al., 2018). In a fluid, sound consists of compressional longitudinal waves (rarefactions and compressions), while in a solid, sound propagates either as a longitudinal or a transverse wave. Sound waves transfer energy through the vibrations of the medium generated by the sound source such as an oscillating object.

Humans can perceive an extremely wide range of frequencies. The threshold of human hearing for a normal adult is about $20 \mathrm{~Hz}$, while the upper limit is $20 \mathrm{kHz}$. This is three orders of magnitude difference! The range of frequencies perceivable by different species is shown in Table 1 (Ahlborn, 2004).

Table 1. Ranges of frequencies perceivable by different species

\begin{tabular}{lcc}
\hline \multicolumn{1}{c}{ Species } & Lower frequency of sound $(\mathbf{H z})$ & Upper frequency of sound $(\mathbf{H z})$ \\
\hline Humans & 20.00 & 20,000 \\
Dogs & 50.00 & 45,000 \\
Cats & 45.00 & 85,000 \\
Bats & 20.00 & 120,000 \\
Dolphins & 0.25 & 200,000 \\
Elephants & 5.00 & 10,000 \\
Birds & $1,000.00$ & 4,000 \\
\hline
\end{tabular}

The physical properties of the sound waves influence the physiological features of sound: its loudness, pitch, and timbre. The energy transmitted by a sound wave $(E)$ per unit of time $(t)$ is called the power of the sound wave $(P)$ :

$$
P=\frac{E}{t} \Rightarrow[P]=\frac{\text { joules }}{\text { second }}=\text { watts }(\mathrm{W})
$$


Since sound waves spread isotropically, one can calculate how much energy is transmitted per unit area $S$, located a distance $r$ from the source. This quantity is called the sound intensity $(I)$ and can be described as the power transmitted by the wave per unit area:

$$
I=\frac{E}{t \times S}=\frac{P}{S}=\frac{P}{4 \pi r^{2}}
$$

The sound intensity is measured in watts per square meter: $[I]=\frac{\mathrm{w}}{\mathrm{m}^{2}}$.

So far, we have focused on the physical description of sound waves. In addition, we have to consider the range of sound intensities perceptible by humans, as well as how our ears perceive sound. Examining sound perception helps justify why the concepts of logarithms and a logarithmic scale are used to describe sound intensity.

There is almost 16 orders of magnitude difference between the softest sound an average human can hear $\left(I_{0}=10^{-12} \frac{\mathrm{W}}{\mathrm{m}^{2}}\right)$ and the loudest sound that will completely destroy our hearing by bursting our eardrums $\left(I_{\max }=10^{4} \frac{\mathrm{W}}{\mathrm{m}^{2}}\right)$ (Table 2). To describe a physical quantity with such a vast range of values, it is common to utilize a logarithmic scale. This scale is especially convenient for achieving a manageable range of numbers. Thus, the sound level, $\beta$, was originally defined as the logarithm of the ratio of the given sound intensity and the softest sound perceivable by humans, $I_{0}$ :

$$
\beta(\text { in } \mathrm{B})=\log \frac{\mathrm{I}}{I_{0}}, \text { where } I_{0}=10^{-12} \frac{\mathrm{W}}{\mathrm{m}^{2}}
$$

Sound level is measured in bel (1 B), in honour of Alexander Graham Bell (18471922), a Scottish-born inventor, scientist, and engineer who patented the first telephone, the phonograph (gramophone), and a few other devices. However, this unit is too large (imprecise) to be useful, thus it was suggested that one tenth of the unit, the decibel or $\mathrm{dB}$ where $1 \mathrm{~B}=10 \mathrm{~dB}$ be used. Today, the sound level is most often measured in dB:

$$
\beta(\text { in } \mathrm{dB})=10 \log \frac{I}{I_{0}}, \quad\left(I_{0}=10^{-12} \frac{\mathrm{W}}{\mathrm{m}^{2}}\right)
$$

There is another reason why the $\mathrm{dB}$ sound level scale is useful. Our ears respond logarithmically to changes in intensity (Gray, 2000) and this is what a logarithmic scale is constructed to display. How our ears perceive the change in loudness depends 
on the ratio between the original and current sound intensities. Let us illustrate what this means with the following example.

Let us assume that the sound level increases from $10 \mathrm{~dB}$ to $20 \mathrm{~dB}$. What is the perceived increase in the loudness of sound and what is the increase in sound intensity? We have:

$$
\beta_{1}=10 \mathrm{~dB} ; \beta_{2}=20 \mathrm{~dB} \text {, therefore } \Delta \beta=10 \mathrm{~dB}
$$

We need to find the ratios between the initial and final sound intensities, that is, $\frac{I_{2}}{I_{1}}$. We will show that the change of sound level of $10 \mathrm{~dB}$ means that the intensity of the sound, $I$, increased tenfold.

$$
\begin{gathered}
\beta_{1}=10 \mathrm{~dB} \Rightarrow 10 \log \frac{I_{1}}{I_{0}}=10 \Rightarrow \log \frac{I_{1}}{I_{0}}=1 \Rightarrow \frac{I_{1}}{I_{0}}=10 \\
I_{1}=10 I_{0} \Rightarrow I_{1}=10^{-11} \frac{\mathrm{W}}{\mathrm{m}^{2}} \\
\beta_{2}=20 \mathrm{~dB} \Rightarrow 10 \log \frac{I_{2}}{I_{0}}=20 \Rightarrow \log \frac{I_{2}}{I_{0}}=2 \Rightarrow \frac{I_{2}}{I_{0}}=100 \\
I_{2}=100 I_{0} \Rightarrow I_{2}=10^{-10} \frac{\mathrm{W}}{\mathrm{m}^{2}}=10 I_{\mathrm{A} 1}
\end{gathered}
$$

Thus, a sound level change from 10 to $20 \mathrm{~dB}$ means that the final intensity is tenfold the original one (Eq. 2). Similarly, a change from 20 to $30 \mathrm{~dB}$, or any other 10 $\mathrm{dB}$ increase, will result in a tenfold increase of the original intensity. This derivation follows from the sound level definition (Eq. 1). It relies on a direct application of the rules of operations of logarithms. While a student might think that a $20-\mathrm{dB}$ sound is twice more intense than a $10-\mathrm{dB}$ one, this is not the case. The power delivered to the ear in the second case is 10 times the original power (Eq. 2).

The difference between the perception of sound and the actual amount of energy reaching our ears is the key to understanding why the logarithmic scale is used in describing the sound intensity. This difference follows from our physiology. Our ears function according to a logarithmic and not to a linear scale. This is the topic of psychoacoustics - the study of how humans perceive sound.

To develop intuition regarding the sound level measurement, one can consider how we perceive different sounds and how much power is delivered in each case (Table 2). 
Table 2. Sound intensity levels perceptible by humans and corresponding phenomena (The Physics Hypertextbook https://physics.info/intensity) and relevant physical phenomena

\begin{tabular}{|c|c|c|}
\hline $\begin{array}{l}\text { Sound } \\
\text { intensity } \\
\text { level } \beta(\mathrm{dB})\end{array}$ & $\begin{array}{l}\text { Intensity, I, } \\
\left(\mathrm{W} / \mathrm{m}^{2}\right)\end{array}$ & Example/effect \\
\hline$-\infty$ & 0 & Absolute silence \\
\hline-24 & $1 \times 10^{-14.4}$ & $\begin{array}{l}\text { sounds quieter than this are not possible due to the random motion of } \\
\text { air molecules at room temperature }(\Delta P=\underline{1.27 \mu P a})\end{array}$ \\
\hline-20.6 & $1 \times 10^{-14.06}$ & Current world's quietest room (Microsoft Building, Redmond, WA, USA) \\
\hline-9.4 & $1 \times 10^{-12.94}$ & former world's quietest room (Orfield Lab, Minneapolis, MN, USA) \\
\hline 0 & $1 \times 10^{-12}$ & $\begin{array}{l}\text { Threshold of hearing at } 1000 \mathrm{~Hz} \text {, reference value for sound pressure of } \\
20 \mathrm{mPa}\end{array}$ \\
\hline 10 & $1 \times 10^{-11}$ & Normal breathing, rustling of leaves \\
\hline 20 & $1 \times 10^{-10}$ & Whisper at $1 \mathrm{~m}$ distance \\
\hline 30 & $1 \times 10^{-9}$ & Quiet home \\
\hline 40 & $1 \times 10^{-8}$ & Average home \\
\hline 50 & $1 \times 10^{-7}$ & Average office, soft music, quiet residential area \\
\hline 55 & $1 \times 10^{-7.5}$ & Dishwasher, electric shaver, electric toothbrush, large office, rainfall \\
\hline 60 & $1 \times 10^{-6}$ & Normal conversation, quiet TV \\
\hline 70 & $1 \times 10^{-5}$ & $\begin{array}{l}\text { Noisy office, busy traffic, air conditioner, automobile interior, } \\
\text { alarm clock, background music, loud television, vacuum cleaner, } \\
\text { washing machine, hair dryer, flush toilet }\end{array}$ \\
\hline 80 & $1 \times 10^{-4}$ & $\begin{array}{l}\text { Loud radio, coffee grinder, noisy restaurant, ringing telephone, } \\
\text { whistling kettle, blender, doorbell, food processor }\end{array}$ \\
\hline 86 & $1 \times 10^{-3.4}$ & $\begin{array}{l}\text { Inside a small single engine plane, such as Cessna, or twin engine such as } \\
\text { Piper Seminole }\end{array}$ \\
\hline 90 & $1 \times 10^{-3}$ & $\begin{array}{l}\text { Inside a heavy truck or a tractor, very heavy traffic, hand saw, } \\
\text { lawn mower, machine tools. Sound generated by Niagara Falls Prolonged } \\
\text { exposure is dangerous }\end{array}$ \\
\hline 100 & $1 \times 10^{-2}$ & $\begin{array}{l}\text { Noisy factory, siren at } 30 \mathrm{~m} \text {, electric drill, shouted conversation, tractor, } \\
\text { truck. Exposure of } 8+\text { hours a day is dangerous }\end{array}$ \\
\hline 110 & $1 \times 10^{-1}$ & $\begin{array}{l}\text { Shouting or barking in the ear, boom box, factory machinery, motorcycle, } \\
\text { school dance, snow blower, snowmobile, } \\
\text { squeaky toy held close to the ear, subway train, and woodworking class. } \\
\text { Serious damage from } 30 \text { min per day exposure. }\end{array}$ \\
\hline 113 & $1 \times 10^{-1}$ & Loudest clap (Alastair Galpin, New Zeeland, 2008) \\
\hline 120 & 1 & $\begin{array}{l}\text { Loud rock concert, pneumatic chipper at } 2 \mathrm{~m} \text {, a clap of thunder, } \\
\text { threshold of pain }\end{array}$ \\
\hline 130 & $1 \times 10^{1}$ & Baby cry, peak stadium crowd noise \\
\hline 140 & $1 \times 10^{2}$ & Jet airplane at $30 \mathrm{~m}$. Severe pain, damage in seconds \\
\hline 150 & $1 \times 10^{3}$ & $\begin{array}{l}\text { Jet aircraft at a few meters, during take-off; explosive blast. Severe pain, } \\
\text { instantaneous damage }\end{array}$ \\
\hline 160 & $1 \times 10^{4}$ & Bursting of eardrums \\
\hline
\end{tabular}


It takes effort to gain an intuitive understanding of how sound intensities can be described using a logarithmic scale. The lack of exposure, as well as an inherent complexity associated with logarithms, contribute to many difficulties that students experience when learning these concepts. We attend to research that explored some of these difficulties in the next section.

\subsection{Brief overview of prior research on sound and logarithms}

Research has shown that the concepts of logarithms and a logarithmic scale pose substantial challenges for students. Even after learning the procedures of operating with logarithms, student conceptual understanding is often lacking (Berezovski \& Zazkis, 2006; Berger et al., 1987; Liang \& Wood, 2005; Weber, 2016).

For example, Liang and Wood (2005) analysed secondary students' misconceptions related to logarithms. They classified these misconceptions into three categories: (1) knowledge or computational errors, (2) understanding errors, and (3) application errors. The first category comprised routine questions that required direct recall or application of the definition and laws of logarithms, or simple manipulations requiring a minimal number of steps. Not surprisingly, $86 \%$ of the students were able to answer these questions correctly. Yet, when the questions became more complex, where students had to decide how to apply their understanding to a slightly unfamiliar situation, only $66 \%$ of them were able to provide a correct answer. Finally, only $39 \%$ of the students were able to solve questions that required applying their understanding to a novel situation.

Several studies focused on students' misconceptions related to the basic properties of mechanical waves, such as sound (Periago et al., 2009). For example, many students found it difficult to visualize how waves can transfer energy without transferring matter. In the case of longitudinal waves such as sound, this becomes even more complicated. The properties of waves and their interrelationships are also often confused, such as loudness of sound and its pitch. Yet, the investigation of sound level provides an additional complication where the human perception of sound and the immense range of sound intensities provide an obstacle for the students who are used to dealing with linear scales and with small ranges of quantities. The mathematical description of sound level using a logarithmic scale creates an additional obstacle. 


\section{Theoretical framing}

The key premise of this study is that effective teaching is based on the teachers' deep and extensive content understanding, at the level exceeding the one required from students. Paraphrasing a famous mathematician and educator, Felix Klein (2004), one might say that teaching requires educators to acquire an advanced standpoint on the subject. Thus, in order for teachers to become effective, they have to understand the concepts they ought to teach in great depth. But what does it mean "to understand in-depth"? Science and mathematics educators have developed different conceptualizations of this notion.

Richard Skemp's original conceptualization of understanding in mathematics distinguished between instrumental and relational understanding (Skemp, 1976). Instrumental understanding refers to the ability to perform procedures, without necessarily being aware of the reasons behind them. This kind of understanding relies heavily on rote memorization and is driven by the question of how and not why. A classic example of instrumental understanding, and how deeply it is ingrained in the teaching of mathematics, is a well-known phrase used to "help" students learn to divide fractions: "You don't need to know why, just invert and multiply" (Ma, 1999; Milner-Bolotin, 2018a, 2018b). Note that the emphasis here is not on the why, but on the how.

Instrumental understanding is not unique to mathematics. For example, in science students recognize patterns and match problems with equations, often without gaining a deeper conceptual understanding of the process or even recognizing various ways of representing the same concepts. In science, instrumental understanding is often expressed by a student ability to solve problems when recognizing patterns and matching givens with formulas, while stumbling with conceptual problems requiring the making of predictions by applying science laws to everyday life (Hake, 1998).

Skemp also described relational understanding, which focuses on the reasons and justifications on connections between different concepts and on applications. In science education, it is often referred to as conceptual understanding (MilnerBolotin, 2014). This is in accordance with the distinctions made by Hiebert (1986) between procedural and conceptual knowledge. Conceptual knowledge has been defined as understanding of the principles and relationships that underlie a domain (Hiebert \& Lefevre, 1986) or knowing why, while the core of procedural knowledge is in knowing algorithms and rules for completing tasks and procedures. 
Similar descriptions were provided by other researchers. For example, RittleJohnson and Alibali's (1999) empirical study about conceptual and procedural knowledge in mathematics defined them as follows:

We define conceptual knowledge as explicit or implicit understanding of the principles that govern a domain and of the interrelations between pieces of knowledge in a domain. We define procedural knowledge as action sequences for solving problems. (p. 175)

Educators argued for the facilitation of students' conceptual development, noting that a large part of mathematics instruction focusses on procedures and skill development (Hiebert \& Grouws, 2007). However, distinguishing "knowledge of procedures" and "knowledge of concepts and relationships" did not provide information about the depths or quality of knowledge. While the conceptualprocedural distinction was adopted by many researchers, Star $(2005,2007)$ criticized the implicit preference of educators toward conceptual knowledge, arguing that many scholars who are interested in mathematics teaching and learning, tend to conceive of conceptual and procedural knowledge as types of knowledge rather than in terms of qualities of knowledge. Star (2005) argued:

\begin{abstract}
The term conceptual knowledge has come to encompass not only what is known (knowledge of concepts) but also one way that concepts can be known (e.g., deeply and with rich connections). Similarly, the term procedural knowledge indicates not only what is known (knowledge of procedures) but also one way that procedures (algorithms) can be known (e.g., superficially and without rich connections). (p. 408)
\end{abstract}

In order to disentangle knowledge type and knowledge quality, Star (2005) introduced a further refinement by making a distinction between deep procedural knowledge and superficial conceptual knowledge. According to Star, deep procedural knowledge is rich in relationships and may entail the flexible application of procedures. Deep procedural knowledge also entails the ability to choose an appropriate and efficient procedure that justifies its use, while being linked with understanding and critical judgement. Superficial conceptual knowledge, as the term implies, refers to surface level knowledge and the reproduction of known facts. The investigation of this refined distinction is our main focus.

In this study, we are interested in the quality of a teachers' knowledge related to sound level and sound intensity. Our access to teachers' knowledge was through the imagined instructional interactions that they described (see the description of the task 
in Section 4). We used thematic content analysis (Creswell, 2008) of these imagined instructional interactions to uncover and categorize the participants' knowledge for teaching (K4T). In particular, we focused on the idea that sound level is related to logarithms and the logarithmic scale. Acknowledging this relationship demonstrates the connection between concepts in mathematics and science, and can be considered as conceptual knowledge. But simply declaring that there is a connection, points to a superficial conceptual K4T. Deep conceptual K4T can be evident, for example, when using multiple representations, drawing connections with daily experiences, and explaining (rather than citing) underlying relationships.

Guiding students into substituting numbers into formulas correctly, or into memorizing the rules of operations with logarithms, is an indication of procedural K4T. However, deep procedural K4T may be exhibited through the teacher's ability when explaining resulting conclusions, such as "every increase in $3 \mathrm{~dB}$ doubles the intensity", or "every increase in $10 \mathrm{~dB}$ multiplies the intensity by 10 ". The teacher's deep procedural K4T may also be exhibited when guiding students to extrapolate from these conclusions when considering other changes in sound level. Our operational definitions of the categories as related to K4T are summarized in Table 3.

Table 3. Description of four categories of teachers' K4T that guided this study

\begin{tabular}{ll}
\hline $\begin{array}{l}\text { Category of teacher's } \\
\text { K4T }\end{array}$ & Description of the category \\
\hline $\begin{array}{l}\text { Superficial conceptual } \\
\text { Deep conceptual }\end{array}$ & $\begin{array}{l}\text { Declaring connections between concepts without elaboration } \\
\text { Explaining underlying relationships between concepts } \\
\text { Superficial procedural } \\
\text { Focusing on the use of procedures without elaborating on the underlying } \\
\text { principles } \\
\text { Connecting procedures to underlying principles }\end{array}$ \\
\hline
\end{tabular}

In light of the discussion above, this study aims to address the following research question: What do participants' scripts reveal about the scriptwriters' K4T for teaching the topic of sound, in particular the concepts of sound intensity and sound level? 


\section{Methodology}

\subsection{Participants and context}

Twelve future physics teachers participated in the study. They all had an extensive physics background at the tertiary level. Eight of the ten participants had a B.Sc. in Physics, two had an M.Sc. in Physics, one had an engineering degree, and one had a Ph.D. in Astronomy. At the time of the study, the participants were enrolled in a methods course for secondary physics teachers in their teacher education program. This required course was delivered in 39 hours over 13 consecutive weeks. It took place in a physics laboratory, and therefore included both theoretical and hands-on activities related to secondary physics teaching.

\subsection{Scripting Task}

During the course, the participants completed the task, Exploration of Sound, which included composing a script for a play that was referred to as a lesson play (Figure 1). As a preparation for this task, the concept of a lesson play (Section 2.2) was presented and discussed in class. The participants were asked to review the science related to sound waves relevant to the secondary physics curriculum in advance. During class, they discussed the task in small groups. This was followed by a whole class discussion of the underlying concepts, pedagogical approaches, and potential student difficulties. The future physics teachers were then asked to complete the task individually over a two-week period.

The task presents the beginning of a dialogue that features student confusion related to sound measurement. In addition to composing a lesson play, in which the teacher and student characters continue the dialogue and discuss sound levels, the participants were asked to address the following questions:

1. How do you understand the concept of sound level? The way you understand the idea yourself could be different from the way you explain it to students. If this is the case, please indicate how you could clarify the issue to yourself, or to another physics teacher.

2. What are key physics concepts students need to acquire to understand the concept of sound level and how it is measured?

3. What are potential student difficulties, misconceptions or alternative conceptions? 
4. How might a teacher help students understand these concepts? What pedagogical approaches would you recommend and why?

5. What resources did you use to write your Lesson Play that helped you figure it out? (Research papers, pedagogical forums, websites, etc.)

\section{Physics 11: Exploration of sound and its properties}

https://curriculum.gov.bc.ca/curriculum/science/11/physics

https://www.healthlinkbc.ca/health-topics/tf4173

Play Setting: The play is set in a Physics 11 classroom. The students have just finished the intro unit on waves and already had two introductory lessons on sound. They discussed the properties and behaviour of waves, sound characteristics, the phenomenon of resonance, how waves are generated and how they propagate. When the teacher entered the classroom the following week, she noticed a group of students arguing excitedly in the corner about the sound level at the concert they just attended over the weekend:

Student 1: I had a huge headache after the last Saturday's concert. I had | my smartphone app and it measured the sound level there to be $91 \mathrm{~dB}$.

This was hurting my ears and my head for the entire Sunday. I still feel it.

Student 2: I have read that sound levels that are above $85 \mathrm{~dB}$ are harmful to humans, so this is understandable, but that harmful? $91 \mathrm{~dB}$ is less than $10 \%$ higher than the threshold. So $91 \mathrm{~dB}$ should not be such a big deal.

Student 3: It doesn't make sense! I am very confused with this $\mathrm{dB}$ thing. What is it? I have a Sound level app on my smartphone. But what do these measurements mean? This is so confusing.

Teacher: This is an interesting conversation. This is a great opportunity to discuss the concept of sound level and what it means...

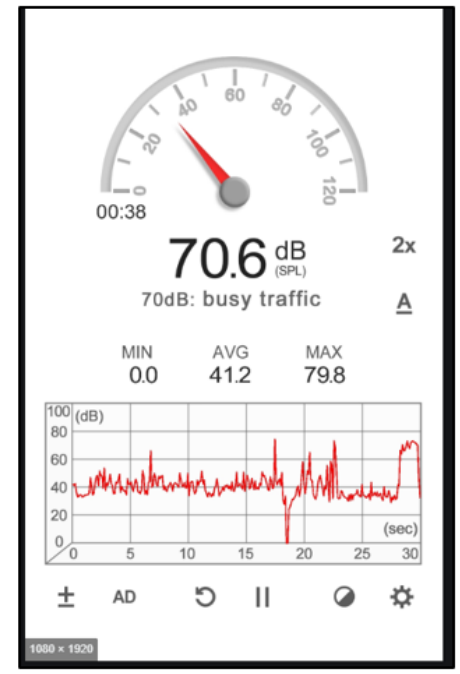

\section{Roles:}

Teacher: A very thoughtful and inspiring new physics teacher

Student 1:

Student 2:

Student 3:

Additional characters:

Figure 1. A scripting task on the topic of sound implemented in the study 


\subsection{Data analysis procedures}

The scripts composed by the participants, along with their responses to the five questions, comprised the data for our study. We have read and analysed all the scripts independently, identified major themes, checked for the accuracy of the explanations and the examples, and considered not only what was present in the scripts, but also what the scriptwriters chose to omit. We then compared our analyses and observations and discussed our interpretations of the data.

\section{$5 \quad$ Results and Analysis}

In this section, we describe four examples illustrating different categories of $\mathrm{K} 4 \mathrm{~T}$ in the context of teaching the topic of sound. While we realize that these categories are not disjoint representations of teachers' $\mathrm{K} 4 \mathrm{~T}$ and can be better represented by a spectrum, we use representative examples from the participants' lesson plays as illustrations. We then discuss how this pedagogical tool can be used in science teacher education to support future teachers in developing their K4T. All the future teachers' names below are pseudonyms.

\subsection{Case 1: Superficial Conceptual K4T}

\subsubsection{Jamie's lesson play}

The teacher-character in Jamie's script began the discussion of sound and its properties by connecting sound phenomena to students' prior experiences. While this was a natural start, most of the interactions during the lesson were factual statements either from the teacher or from the students. It appeared as if Jamie tried to include everything that he could remember about sound and sound waves. Jamie's lesson play included the discussion of many sound properties, such as its sources, frequency, pitch, and loudness. Additionally, the use of PhET simulations, while relevant to the general exploration of sound waves or their interference, was irrelevant to the lesson (Wieman et al., 2010). In Jamie's script, the discussion initiated by the teacher left no sufficient time to focus on the physics and mathematics concepts. The following excerpt illustrates this:

Denny: Oh yeah, what is a dB?

Teacher: Well a dB, or a decibel, is the intensity level you hear the sound at. Notice the Deci prefix in the word decibel is Latin for tenth. The intensity level is 
relative to something we call the Threshold of Hearing, which is o dB. And its logarithmic after that. The difference between $10 \mathrm{~dB}$ and $20 \mathrm{~dB}$ is 10 times greater.

Sanders: Okay, what? So, decibels are on a logarithmic scale?

Wendy: So, if I heard something at $30 \mathrm{~dB}$, does that mean it is a thousand times greater than $1 \mathrm{~dB}$ ? Or if a sound was $70 \mathrm{~dB}$, and I heard something at $90 \mathrm{~dB}$, it is 100 times louder?

Teacher: Correct. [...]

Wendy: What I thought that was a small 10\% difference in threshold is a lot. As the scale gets higher, the magnitude is much greater, it's not a linear relationship with the threshold of hearing.

Teacher: So now you know! We must treasure our hearing. Let's set this on a scale now. Using Health-BC, sounds that are harmful are above $85 \mathrm{~dB}$, and the concert at $91 \mathrm{~dB}$ is like a subway, or a shouting conversation. That is loud! Especially over a long period of time, you are putting your ears against very different frequencies, to overly large amplitudes...

\subsubsection{Analysis of Jamie's lesson play}

This excerpt illustrates why we categorized this script as an example of Superficial Conceptual K4T, as it is rife with lost opportunities for supporting student conceptual understanding. Jamie's script also shows how teacher's Superficial Conceptual K4T could reinforce students' misunderstanding and confusion. For instance, there was no explanation of why the 20-decibel difference meant a hundred-fold increase in sound intensity. It is unclear why a logarithmic scale was chosen to describe the sound level. On one hand, a lot of complex information was given to the students without any explanation, on the other hand, the teacher discussed the meaning of the prefix Deci used in the name of the sound level unit (decibel). This was a striking example of a "pedagogical shield" (Koichu \& Zazkis, 2013; Marmur \& Zazkis, 2018; Zazkis \& Leikin, 2008), that is, certain pedagogical choices made by teachers to protect them from exposing their inability to attend to the core of the task.

In the reflection, Jamie acknowledged having a rather shallow understanding of the content, yet he did not try to delve deeper into it. The topics of logarithms and the logarithmic scale were hardly mentioned in the script and were not elaborated upon. This is how Jamie described it: "I was confused about the approach I would take... I really wasn't sure what sound level meant." 


\subsection{Case 2: Deep Conceptual K4T}

\subsubsection{Alex's lesson play}

We illustrate Deep Conceptual K4T with the case of Alex, who approached the discussion of sound level and sound intensity without requiring students to delve into any formal calculations. Alex split the script into three scenes. Scene 1 introduced students to the concept of sound level by combining their perception of sound loudness and the measurement of the sound level. This part had an experiential focus and culminated with identifying the discrepancies between students' prior knowledge and the results of their experiences of measuring sound levels with their smartphones. In Scene 2, a more formal definition of sound intensity was introduced and the students were given a version of Table 2. In Scene 3, the students returned to the initial problem to reconcile their original measurement of a 3 -decibel increase in sound level when doubling the number of sound sources.

Alex realized that while a notion of loudness of sound was familiar to the students from everyday life, the concepts of sound level and intensity were not. Moreover, the students did not possess the necessary mathematical background of logarithms to approach this subject computationally. Consequently, the teacher-character in Alex' script supported students in acquiring conceptual understanding without reverting to calculations. To do that, she used a smartphone application that could measure the ambient sound level, so the students experienced the differences in sound levels first hand. This was a deliberate pedagogical choice related to technology use, as students today have access to smartphones, but few use this powerful tool for work in mathematics or science (Maciel, 2015; Milner-Bolotin, 2016).

Alex intended to help her students understand what the concepts of sound intensity and sound level represented through the physical experiences of sound and its measurement. To achieve this, the teacher-character in Alex's lesson play spread the students around the classroom and asked them to measure the sound levels produced by one and then by two identical xylophones:

Teacher: That's interesting. So, if that's true, that would mean that the decibel scale doesn't measure how loud the original sound was, it measures how loud it is when it gets to you. Now, the other interesting thing is how the number changed. I want to do another demo to make that clearer. Everyone measure and write down how loud this one xylophone is in $\mathrm{dB}$. [The teacher plays one key of one xylophone.] Now, if I played two xylophones and hit just as hard, how loud do you expect it to be compared to just one xylophone? 
While the teacher in this script never discussed the logarithmic scale, she challenged the students to think about what would happen if instead of a single sound source (e.g., a xylophone), there were two identical sources. This easy to perform experiment has a significant pedagogical value, and reveals Alex's Deep Conceptual $\mathrm{K} 4 \mathrm{~T}$, as illustrated by the following dialogue:

Jiyun: Well, it should be twice as loud because there's two.

Teacher: Great, our first suggestion is twice as loud. Any other suggestions? [The class shakes their heads.] Okay, let's measure it. Don't say your number right away. [The Teacher plays both xylophones at once.] Okay everyone, write down what your phone measured. Now, I want to ask everyone, did the xylophones sound twice as loud as one xylophone? Did you feel like your ears were dealing with twice as much sound?

Julia: I think so.

Austin: Not really! It only sounded a little louder than one xylophone. Like, I could tell there were two, but it didn't hurt my ears or anything.

Teacher: Okay, we have two different opinions! Let's see which one matches how the decibel scale measures. Everyone, please summarize your two measurements.

Julia: $\quad$ I got 75 and 78.

Austin: I got 65 and 69 .

Jiyun: $\quad$ I got 70 and 72.

This dialogue illustrates how comparing the measurements of the sound levels of one versus two identical sources can help students develop a conceptual understanding of the key property of $\operatorname{logarithms}, \log (a b)=\log (a)+\log (b)$, and the correspondence between linear and logarithmic scales. The teacher-led the students through having an experience of the logarithmic scale, used to measure sound level, without actually realizing that they were using such a mathematical construct. Having two sound sources instead of one does not double the $\mathrm{dB}$ value, but adds $3 \mathrm{~dB}$ to the original one. In this script, the students experienced how the measurement of the sound level created by two xylophones added about $3 \mathrm{~dB}$ to the original sound level. In the follow-up lesson, the teacher introduced the table demonstrating the sound level and sound intensity connection (Table 2), and asked the students to discuss the patterns they might have noticed, thereby connecting what the students observed with their earlier experiences. Thus, the lesson came to a full circle. 


\subsubsection{Analysis of Alex's lesson play}

Alex's choices in the lesson play pointed to her Deep Conceptual K4T. Alex identified key physical, physiological, and mathematical concepts involved in teaching this topic. Through considering potential student difficulties, by evoking powerful examples, and asking questions that encouraged students to confront their own understandings, Alex built on students' prior knowledge yet expanded it while bridging multiple representations of the phenomenon. Her thoughtful approach was based on juxtaposing intuitive student understanding of sound level with its direct measurement using a smartphone application. While Alex avoided introducing a rigorous mathematical description and computational approaches in the script, she helped students build some intuitive conceptual understanding. The deliberate and pedagogically rich choices made in this script were informed by Alex's own understanding of the concept and her awareness of student conceptual difficulties. As Alex wrote in her reflection:

Talking about sound is difficult because there are a lot of concepts. When you decide to shift the focus of your lesson on the spot you may not have a lesson properly scaffolded for the concept. I am okay at checking for understanding, but my imaginary teacher was not always checking whether people were silent because they did or did not understand.

Alex recalled from her undergraduate physics courses that describing sound intensity required some "advanced mathematics". Yet, Alex decided to help students build conceptual, intuitive understanding, which in turn required the teacher to have a deep understanding of the subject matter. This is how Alex described it:

I hadn't studied sound of decibels for a long time, and all I remembered was the core math. I had to do a lot of research about air pressure, sound waves, intensity and sound level, and even though air pressure wasn't explained in depth in the lesson play, having extra understanding was really important for knowing how to best help the students. You need to understand a subject much deeper if you want to teach the basics.

This lesson play demonstrates Alex’s Deep Conceptual K4T. While she refrained from using procedural knowledge when calculating sound level, her approach could be considered as an important first step in introducing students to the concepts of logarithms and the logarithmic scale. 


\subsection{Case 3: Superficial Procedural K4T}

\subsubsection{Valery's lesson play}

Valery's lesson play exemplifies Superficial Procedural K4T. Valery had a solid understanding of the relevant concepts and was aware of related student difficulties. In the reflection, he reminisced about an undergraduate physics course where these topics were discussed in detail, as they were still fresh in his memory. For example, Valery clearly distinguished the concepts of loudness and sound intensity. In the words of his teacher-character, Valery emphasized that human perception of sound and the vast range of sound intensities were the reason for choosing a logarithmic scale for describing this phenomenon. He also stressed the difference between the linear and logarithmic scales and how they are used to describe sound properties:

Teacher: ... I know that all of you are very comfortable with linear scales. If I double a certain quantity, then the number with its associated unit is doubled as well. This does not work when talking about decibels. If I speak at $50 \mathrm{~dB}$, then double the sound intensity, I do not speak at $100 \mathrm{~dB}$. I will now give you a short introduction to logarithms, and in pre-calculus 12 next year, you will go more in depth learning about them.

Teacher writes the following equation on the board: $\beta=10 \log \frac{I}{I_{0}}$.

This is equation we use when we talk about sound intensity measured in decibels. The $\log (x)$ says to take the logarithm of the quantity in the parentheses, using base 10. This can be done by using the log function on your calculator. As an example, I want you all to calculate what the logarithm of 10 is in base 10 .

At this moment in the script, the teacher-character realized that the students might not have studied logarithms in their mathematics classes, so the focus was turned to the procedure for calculating logarithms using calculators. The teachercharacter even told the students that while they might not know what these calculations meant, they would later learn it in their mathematics class. Then, the teacher-character mentioned to the students that "In math, the logarithm is an inverse of the exponential". The teacher focussed on the steps of how to calculate logarithms and interpret a logarithmic scale. The teacher also tried to help students gain some intuitive understanding of a logarithmic scale by showing an example of $10^{\circ}$ and $10^{2}$, emphasizing that the second number is 100 times larger than the first one, while the second exponent is only two steps removed from the first one. The teacher in Valery's 
script stated "... so even though the two values are 2 units apart, they actually stand for a factor of 100 between them!" From this moment on, the lesson focussed on calculating different sound levels and comparing the sound of $86 \mathrm{~dB}$ with $91 \mathrm{~dB}$. The teacher led the students in deriving the expression which showed that the intensity of the 91-decibel sound is almost 4 times larger than the intensity of the 86-decibel sound. In this script, the students followed the teacher's derivation written on the board, confirming that it all made sense to them now:

Teacher: Hopefully you feel better, Jerry! Back to your initial guess, Leah. You were on the right track. The only thing you have to keep in mind about the decibel scale is the $(10 \mathrm{~dB})$ term in front. You need to combine that with your exponents to properly compare the two decibel values, like such.

Teacher writes on the board: $10^{\frac{91-85}{10}} \sim 3.98$.

This was a surprising culmination of the lesson, as it is unclear if the students would be able to justify or even follow these steps. To understand the approach to solving this problem, one needs to be familiar with logarithms and the definition of sound level. For some reason, the teacher in Valery's play skipped these steps and only showed the students the final solution. Thus, the entire lesson culminated in a mathematical procedure while ignoring the reasons for it.

\subsubsection{Analysis of Valery's lesson play}

This lesson play presents a teacher who has deep knowledge of the underlying concepts from both a mathematics and a physics perspective. Yet, Valery chose to focus on the procedures or the steps the students have to go through in order to calculate and compare different sound levels and the sound intensities associated with them. Moreover, while focussing on the procedures, a lot of teachable moments were lost, that could have been used to help students make sense of the fascinating properties of logarithms. As such, we consider Valery's pedagogical choices as an example of Superficial Procedural K4T.

In his reflection, Valery wrote the following:

I learned this topic in first-year university and so I was well equipped mathematically compared to grade 11 students. Introducing new math functions in a physics class before a math class is not anything new, but I think it is more impactful at the secondary school level. 
Surprisingly, Valery did not use a table of various sound intensities (Table 2) to illustrate an exponential growth, and did not compare linear and logarithmic scales using graphical representations. Instead, Valery chose to spend most of the time on the procedural steps of how to calculate the sound level and not why sound level is calculated in this way. We show how both the why and the how could be incorporated into the lesson play in the final example.

\subsection{Case 4: Deep Procedural K4T}

\subsubsection{Chris's lesson play}

Chris's lesson play illustrates Deep Procedural K4T. While reflecting on the connection between mathematics and science, she wrote:

I would want to use the example they were talking about. As physicists, this is part of what we do: poke at problems with math. During the lesson I want to give them an opportunity to make noise and measure the resulting sound level in decibels. I would also want to give them at least one other example of a logarithmic scale.

This reveals that Chris is ready to help students bridge mathematical and physical representations with experimental evidence. Chris realized that the students might find it difficult to connect linear and logarithmic scales and decided to expand on it in her lesson play. As such, the teacher-character in Chris's script began by helping students generate experimental evidence through using a smartphone application that measured the sound level of a thud created by a falling textbook.

Sam: $\quad$ Maybe sound adds up. Like, if we are talking and we drop a textbook it will measure the combined sound.

Teacher: Yes, we're aiming to measure the sound of one thing at a time, so we don't want the app to pick up other sounds. Ok, who wants to go first?

Pippin: Me! Ready with your app, Merry? $3 \ldots 2 \ldots 1 \ldots$ [drops textbook on to desk]

Merry: That was [some number] dB. Teacher: Alright. I would like to go next. [Rustles paper.]

Merry: That was [some other number] dB. Sam: Can I go next?

Teacher: Go ahead. Sam taps a ruler on a desk. Merry: That was [yet another number] dB. 
Teacher: The loudness seems to change a lot, are the number of decibels changing a lot too?

Merry: Only from the super quiet sounds to the louder sounds.

In this dialogue, the teacher-character supported students in making connections between linear and logarithmic scales. The students heard a significant increase in the loudness and juxtaposed it with the "small change" in sound level as expressed on a decibel scale. This is important, as up to this point the teacher had not introduced the mathematical description of the sound level. Only at this point, the teacher introduced the formula connecting the sound level with the sound intensity. The teacher prefaced the sound level formula by saying, "Because we are physicists, we can write down how sound level depends on intensity in a formula." The teacher then helped the students connect the mathematical description of sound level to the students' physical experiences of loudness:

Teacher writes $\beta$ (in $\mathrm{dB})=10 \log I / I_{o}$ on the board.

Teacher: Where beta is the sound level, $I$ is the intensity of the sound wave we are interested in, and $I o$ is the intensity of the quietest sound that a good ear can hear. The logarithm is base 10. What happens if $I$ is equal to $I_{0}$ ?

Frodo: Then you have log of one.

Teacher: Does beta equal zero?

Merry: No, because there's still sound.

Teacher draws a logarithmic curve on the board.

Sam: $\quad$ Wait, I remember this from math. $\log (1)=0$. So, if $I=I_{0}$, then $\beta=0 \mathrm{~dB}$.

Teacher: So, if I measure $0 \mathrm{~dB}$, does that mean there is no sound?

Frodo: No, because to get $0 \mathrm{~dB} I$ has to be the same as $I_{0}$.

Teacher: That's right, and $\mathrm{I}_{0}$ is the quietest sound a human can hear...

It is noteworthy how connections between mathematical and physical representations of the phenomenon were made. For example, instead of introducing the concept of the threshold of hearing, the teacher invited the students to see for themselves the meaning of $I_{0}$ - the quietest sound they could hear. Then the teacherled the students through the steps of the mathematical description: 
Teacher: Let's return to the physics and start thinking about louder sounds now, $I_{0}=$ $1.0 \times 10^{-12} \frac{\mathrm{W}}{\mathrm{m}^{2}}$ [writes Io value on the board, is a given, it's]. Sam, you were right that sound levels above $85 \mathrm{~dB}$ can do damage. Can we use this formula [points at formula on the board] to find the intensity of the sound wave for that sound level?

Pippin: I can't. I don't like logs.

Teacher: From general properties of logarithms, if $\log$ base $\mathrm{b}$ of $\mathrm{n}$ equals $\mathrm{a}$, then $\mathrm{n}$ is $\mathrm{b}$ to the exponent a. [Writes equations as she speaks: $\log _{b}(n)=a \rightarrow b^{a}=n$.

Sam: I don't like logs either, but with this information I think I can rearrange the formula.

Teacher: Go ahead and give it a try. We are looking for the intensity given that the sound level is $85 \mathrm{~dB}$ and $I_{0}=1.0 \times 10^{-12} \frac{\mathrm{W}}{\mathrm{m}^{2}}$.

Students attempt calculation.

Teacher: When I rearrange the formula, I get $I=I_{0} 10^{\beta / 10}$. [writes formula on board]. Then, given $\beta=85 \mathrm{~dB}$ and $I_{0}=1.0 \times 10^{-12} \frac{\mathrm{W}}{\mathrm{m}^{2}}, I=3.2 \times 10^{-4} \frac{\mathrm{W}}{\mathrm{m}^{2}}$. Let's do the same for $91 \mathrm{~dB}$. What is $I$ for $85 \mathrm{~dB}$ compared to $I$ for $91 \mathrm{~dB}$ ?

Merry: $\quad$ I get $1.3 \times 10^{-3}$.

Teacher: Always remember to state your units. You got $1.3 \times 10^{-3}$ what?

Merry: $\quad$ Right, $\frac{\mathrm{w}}{\mathrm{m}^{2}}$.

Teacher: So, what is $I$ for $91 \mathrm{~dB}$ over $I$ for $85 \mathrm{~dB}$ ?

Sam: Just about 4 !

Pippin: Always state your units!

Teacher: Well, in this case we've taken something in Watts per meter squared and divided by something also in Watts per meter squared, so we get a unit-less number.

Merry: $\quad$ So, $91 \mathrm{~dB}$ is like 4 times more intense than $85 \mathrm{~dB}$, even though the difference in the number isn't that big. That's so weird!

The students in the script discussed ratios of sound intensities and how these ratios could be expressed using a logarithmic scale and decibels. They connected different mathematical representations of the same phenomenon.

The teacher-character led the students through the mathematical procedure while realizing that some students might be apprehensive of it. Yet, the teacher decided not 
to avoid the mathematical procedure but instead helped the students develop the mathematical skills necessary when dealing with logarithms. The teacher also described how the logarithmic scale is used to describe earthquakes.

The script culminated with the teacher asking the students to calculate the ratio of intensities for 85-decibel and 91-decibel sounds. The teacher modelled the derivation for the calculation on the board by starting with the log rule that students should be already familiar with, $\log (x)-\log (y)=\log \left(\frac{x}{y}\right)$. Finally, the teacher used this rule to help students derive the difference in sound levels between two sounds, $\beta_{2}-\beta_{1}=$ $10 \log \left(\frac{I_{2}}{I_{1}}\right)$, and then asked the final question:

Teacher: Here is a question to try: what $\beta_{2}-\beta_{1}$ do we need to get $\frac{I_{2}}{I_{1}}=2$ ?

Sam: $\quad$ I get $3.01 \mathrm{~dB}$.

Merry: Wow, only $3 \mathrm{~dB}$.

Teacher: That's right, only $3 \mathrm{~dB}$ to double the intensity. So Merry, does it make sense that your head hurts when you experienced $91 \mathrm{~dB}$ and $85 \mathrm{~dB}$ is where damage will start to occur?

Merry: Yup!

\subsubsection{Analysis of Chris's lesson play}

This lesson play illustrates the merging of the teacher's Deep Procedural K4T. Chris's teacher-character not only led the students through the mathematical representation of the physical phenomenon, but she also anticipated when the students might have potential pitfalls and misconceptions. The teacher seamlessly moved between different representations and made a deliberate effort to connect these representations to the students' everyday life experiences. The chosen juxtaposition of the difference in decibels with the ratios of intensities is a valuable pedagogical approach, in which we also recognise Deep Conceptual K4T.

Chris' reflection also reveals that although she did not have the physics content knowledge prior to designing this lesson play, she was fully capable of acquiring it and making connections to students' lives while helping them with concrete examples of abstract concepts. This is how Chris described it:

I think this is a pretty traditional lesson.... I didn't know much about the topic, so I found the relevant sections in Giancoli [a physics textbook] and introduced concepts as they did. There was some discussion, a bit of 
demonstration in which the students were involved, some exploration of the math, and then a tie-back to the opening question.

\section{Discussion}

This study aimed at addressing the following research question: What do participants' scripts reveal about the scriptwriters' knowledge for teaching the topic of sound, in particular the concepts of sound intensity and sound level? To address this question, we implemented a scriptwriting task (Figure 1) in a methods course for future secondary physics teachers. We found that all of the scripts submitted by the future teachers could fit into one of four broad categories of describing their K4T (Table 3). From analysing future teachers' reflections and juxtaposing them with the scripts, it became clear that future teachers' knowledge of the relevant content was a significant factor in their lesson plays.

When future teachers (e.g., Jamie) felt insecure about their content knowledge, they avoided dealing with the topic directly and digressed into discussing superficial or less relevant issues and avoided any mathematical representations (Superficial Conceptual K4T). This was an example of the pedagogical shield described in the literature (Kontorovich \& Zazkis, 2016). On the other hand, some teachers (e.g., Alex) avoided using complex mathematical representations, but were able to focus on the concepts and helped students connect these concepts to their everyday lives. Those future teachers demonstrated Deep Conceptual K4T. We also found that even if future teachers were confident in their mathematical and science content knowledge (e.g., Valery), this did not guarantee that they would demonstrate Deep Procedural K4T. Few future (e.g., Chris) teachers demonstrated Deep Procedural K4T in their lesson plays.

In their reflections, all of the future physics teachers emphasized the value of the scriptwriting activity. It helped them identify their own pedagogical challenges, while encouraging them to imagine the interactions that might happen in a real secondary physics classroom. The focus on the learning as an interactive dialogical process was something that future physics teachers did not encounter during traditional lesson planning activities. Importantly, all of the future physics teachers emphasized the value of the scriptwriting process in helping spur their pedagogical growth.

Moreover, as the scriptwriting activity occurred over an extended period of time, the future teachers were not limited by the knowledge they already possessed but were encouraged to expand their content and pedagogical horizons. The leading questions 
in the first part of the scripting task (Figure 1) modelled pedagogical experiences of practising teachers preparing for lessons that might be outside of their direct area of expertise. Thus, unlike a traditional lesson plan, the scriptwriting activity provides a fertile ground for challenging future teachers to explore pedagogical approaches when teaching more advanced topics. Furthermore, the scriptwriting activity provides an opportunity for educational researchers to peek into future teachers' $\mathrm{K} 4 \mathrm{~T}$ and consider how teacher educators can help future teachers expand upon it.

\section{Conclusions}

Our study adds to the growing body of research that investigates future science teachers' knowledge for teaching (K4T). The study's particular contributions can be grouped into two major categories. First, while scriptwriting was used in a variety of studies in mathematics education, our contribution is in extending the applicability of scriptwriting to physics education. Scriptwriting invites future physics teachers to imagine possible instructional interactions, student questions, and pedagogical approaches. This may help future physics teachers begin to break down the existing rigid subject matter barriers and to consider how future physics teachers can make their physics lessons more engaging and meaningful for their students.

Second, we extend research on teachers' knowledge related to sound intensity, focusing on how such knowledge plays out in an imaginary teaching scenario. While the measurement of sound intensity is based on logarithms, some of the scriptwriters demonstrated how the mathematics could be highlighted in a manner accessible to students, while others illustrated how mathematics could be avoided without hindering the integrity of the instruction. Our work builds upon the studies of researchers who questioned the traditional facets of knowledge, as conceptual and procedural, and who provided refinement of these notions (Star, 2005). We operationalized the facets of K4T (deep/superficial and conceptual/procedural) in the context of sound intensity and sound level and illustrated them using the participants' scripts.

In light of our findings, we believe that incorporating scriptwriting tasks in mathematics and science teacher education has a number of potential advantages. For teacher educators, this process can reveal both the content and pedagogical knowledge of future teachers, as well as their own misconceptions and challenges. This information is valuable for designing effective methods courses. For researchers, analysing the scripts can guide them towards the design of effective prompts that may 
help generate meaningful scriptwriting tasks for pedagogically powerful experiences for the next group of future teachers. Finally, for future teachers, participating in the scriptwriting activity can help them practise designing and implementing meaningful lessons in a non-threatening and reflective environment while gaining confidence and expanding their $\mathrm{K} 4 \mathrm{~T}$.

\section{Acknowledgements}

We would like to thank anonymous reviewers for their insightful and detailed comments and suggestions for improvement.

\section{References}

Ahlborn, B. (2004). Zoological Physics: Quantitative Models of Body Design, Actions, and Physical Limitations of Animals. Springer Verlag.

Arons, A. B. (1997). Teaching introductory physics. John Wiley and Sons.

Berezovski, T., \& Zazkis, R. (2006). Logarithms: Snapshots from Two Tasks. Proceedings of 3oth International Conference for Psychology of Mathematics Education., Prague, Czech Republic.

Berger, C. F., Pintrich, P. R., \& Stemmer, P. M. (1987). Cognitive consequences of student estimation on linear and logarithmic scales. Journal of Research in Science Teaching, 24(5), 437-450. https://doi.org/10.1002/tea.3660240506

Biggs, J. B. (1987). Student Approaches to Learning and Studying. Research Monograph. Australian Council for Educational Research.

Campbell, P. F., Nishio, M., Smith, T. M., Clark, L. M., Conant, D. L., Rust, A. H., DePiper, J. N., Frank, T. J., Griffin, M. J., \& Choi, Y. (2014). The relationship between teachers' Mathematical Content and Pedagogical Knowledge, teachers' perceptions, and student achievement. Journal of Research in Mathematics Education, 45(4), 419-459. https://doi.org/https://doi.org/10.5951/jresematheduc.45.4.0419

Center for Education Reform. (2018). A nation still at risk? Results from the latest NAEP recall the report from 35 years ago. https://www.edreform.com/2018/04/a-nation-still-at-risk/

Creswell, J. W. (2008). Educational research: Planning, conducting, and evaluating quantitative and qualitative research (3rd ed.). Pearson.

Depaepe, F., Verschaffel, L., \& Kelchtermans, G. (2013). Pedagogical content knowledge: A systematic review of the way in which the concept has pervaded mathematics educational research. Teaching and Teacher Education, 34, 12-25.

https://doi.org/https://doi.org/10.1016/j.tate.2013.03.001

Feynman, R. (1994). The Character of Physical Law (Modern Library Edition ed.). Random House Inc.

Gray, L. (2000). Properties of Sound. Journal of Perinatology, 20, S5-S10.

Grossman, P., Hammerness, K., \& McDonald, M. (2009). Redefining teaching, re-imagining teacher education, Teachers and Teaching. Theory and Practice, 15(2). https://doi.org/ http://dx.doi.org/10.1080/13540600902875340 
Hake, R. R. (1998). Interactive-engagement versus traditional methods: A six-thousand-student survey of mechanics test data for introductory physics courses. American Journal of Physics, 66(1), 64-74.

Hawkes, R., Iqbal, J., Mansour, F., Milner-Bolotin, M., \& Williams, P. (2018). Physics for scientists and engineers: An interactive approach (2nd ed.). Nelson Education.

Hiebert, J. (Ed.). (1986). Conceptual and procedural knowledge: The case of mathematics. Routledge, Taylor \& Francis Group. https://doi.org/https://doi.org/10.4324/9780203063538.

Hiebert, J., \& Grouws, D. A. (2007). The effects of classroom mathematics teaching on students' learning. In J. F. K. Lester (Ed.), Second Handbook of research on mathematics teaching and learning (pp. 371-404).

Hiebert, J., \& Lefevre, P. (1986). Conceptual and procedural knowledge in mathematics: An introductory analysis. In J. Hiebert (Ed.), Conceptual and procedural knowledge: The case of mathematics (pp. 1-27). Routledge: Taylor \& Francis Company. https://doi.org/https://doi.org/10.4324/9780203063538

Klein, F. (2004). Elementary Mathematics from an Advanced Standpoint: Arithmetic, Algebra, Analysis (E. R. Hedrick \& C. A. Noble, Trans.; Vol. 1). Dover Publications.

Koichu, B., \& Zazkis, R. (2013). Decoding a proof of Fermat's Little Theorem via script writing. Journal of Mathematical Behavior, 32, 367-376.

Kontorovich, I., \& Zazkis, R. (2016). Turn vs. shape: Teachers cope with incompatible perspectives on angle. Educational Studies in Mathematics, 93(2), 223-243.

Lakatos, I. (1976). Proofs and Refutations: The logic of mathematical discovery. Cambridge University Press.

Liang, C. B., \& Wood, E. (2005). Working with logarithms: students' misconceptions and errors. The Mathematics Educator, 8(2), 53-70.

Ma, L. (1999). Knowing and teaching elementary mathematics: Teachers' understanding of fundamental mathematics in China and in the United States. Lawrence Erlbaum Associates.

Maciel, T. (2015). Smartphones in the classroom help students see inside the black box. APS News, 24(3), 5-6.

Marmur, O., \& Zazkis, R. (2018). Space of fuzziness: Avoidance of deterministic decisions in the case of the inverse function. Educational Studies in Mathematics, 99(3), 261-275. https://doi.org/https://doi.org/10.1007/s10649-018-9843-2

McDermott, L. C. (2001). Oersted medal lecture 2001: Physics education research: The key to student learning. American Journal of Physics, 69, 1127-1137.

McDermott, L. C., Heron, P. R. L., Shaffer, P. S., \& Stetzer, M. R. (2006). Improving the preparation of K-12 teachers through physics education research. American Journal of Physics, 74(9), 763-767.

Milner-Bolotin, M. (2014). Using PeerWise to promote student collaboration on design of conceptual multiple-choice questions. Physics in Canada, 7o(3), 149-150.

Milner-Bolotin, M. (2016). Promoting Deliberate Pedagogical Thinking with Technology in physics teacher education: A teacher-educator's journey. In T. G. Ryan \& K. A. McLeod (Eds.), The Physics Educator: Tacit Praxes and Untold Stories (pp. 112-141). Common Ground and The Learner.

Milner-Bolotin, M. (2018a). Evidence-based research in STEM teacher education: From theory to practice. Frontiers in Education: STEM Education, October, 14.

https://doi.org/10.3389/feduc.2018.00092 
Milner-Bolotin, M. (2018b). Nurturing creativity in future mathematics teachers through embracing technology and failure. In V. Freiman \& J. Tassell (Eds.), Creativity and Technology in Math Education (pp. 251-278). Springer.

https://www.springer.com/gp/book/9783319723792

Milner-Bolotin, M. (2019). Technology as a catalyst for 21st century STEM teacher education. In S. Yu, H. M. Niemi, \& J. Mason (Eds.), Shaping Future Schools with Digital Technology: An International Handbook (pp. 179-199). Springer. https://www.springer.com/gp/book/9789811394386

Milner-Bolotin, M. (2020). Deliberate Pedagogical Thinking with Technology in STEM Teacher Education. In Y. Ben-David Kolikant, D. Martinovic, \& M. Milner-Bolotin (Eds.), STEM Teachers and Teaching in the Era of Change: Professional expectations and advancement in 21st Century Schools (pp. 201-219). Springer.

https://doi.org/https://doi.org/10.1007/978-3-030-29396-3

Periago, C., Pejuan, A., Jaen, X., \& Bohigas, X. (2009, 22-24 June 2009). Misconceptions about the propagation of sound waves. 2009 EAEEIE Annual Conference,

Rittle-Johnson, B., \& Alibali, M. W. (1999). Conceptual and procedural knowledge: Does one lead to the other? Journal of Educational Psychology, 91(1), 175-189.

https://doi.org/10.1037/0022-0663.91.1.175

Shulman, L. S. (1986). Those who understand: Knowledge growth in teaching. Educational Researcher, 15(2), 4-14. http://www.jstor.org/stable/1175860

Shulman, L. S. (1987). Knowledge and teaching: Foundations of the new reform. Harvard Educational Review, 57(1), 1-23. http://her.hepg.org/content/j463w79r56455411/

Skemp, R. R. (1976). Relational Understanding and Instrumental Understanding. Mathematics Teaching, 77, 20-26.

Star, J. R. (2005). Reconceptualizing Procedural Knowledge. Journal for Research in Mathematics Education, 36(5). https://www.jstor.org/stable/30034943

Star, J. R. (2007). Foregrounding Procedural Knowledge. Journal For Research in Mathematics Education, 38(2), 132-135.

Weber, C. (2016). Making logarithms accessible - operational and structural basic models for logarithms. Journal für Mathematik Didaktik, 37(1), 69-98.

https://link.springer.com/article/10.1007/s13138-016-0104-6\#citeas

Wieman, C. E., Adams, W. K., Loeblein, P., \& Perkins, K. K. (2010). Teaching physics using PhET simulations. The Physics Teacher, 48(4), 225-227.

Zazkis, R., \& Kontorovich, I. (2016). A curious case of superscript (-1): Prospective secondary mathematics teachers explain. The Journal of Mathematics Behavior, 43, 98-110.

Zazkis, R., \& Leikin, R. (2008). Exemplifying definitions: a case of a square. Educational Studies in Mathematics, 69(2), 131-148. https://doi.org/10.1007/s10649-008-9131-7

Zazkis, R., Liljedahl, P., \& Sinclair, N. (2009). Lesson plays: Planning teaching versus teaching planning. For the Learning of Mathematics, 29(1), 39-46.

Zazkis, R., \& Marmur, O. (2018). Scripting tasks as a springboard for extending prospective teachers' example spaces: A case of generating functions. Canadian Journal of Science, Mathematics and Technology Education, 18(4), 291-312.

Zazkis, R., Sinclair, N., \& Liljedahl, P. (2013). Lesson play in mathematics education: A tool for research and professional development. Springer.

Zazkis, R., \& Zazkis, D. (2011). The significance of mathematical knowledge in teaching elementary methods courses: Perspectives of mathematics teacher educators. Educational Studies in Mathematics, 76(3), 247-263. 